\title{
Elimination of the biogenic pollution effects on aquatic environments
}

\author{
Vladimir Sherbakov ${ }^{1}$, Konstantin Chizhik ${ }^{2 *}$, Tatyana Shchukina ${ }^{1}$, and Anastasiya \\ Milyaeva ${ }^{1}$ \\ ${ }^{1}$ Voronezh State Technical University, Voronezh, Russia \\ ${ }^{2}$ Moscow State University of Civil Engineering, Moscow, Russia
}

\begin{abstract}
Intensive water consumption from surface sources leads to debit imbalance and high level of pollution, especially for wastewater discharges, including urban wastewater treatment facilities. Dissolved harmful and organic substances enter a large number of water bodies, which leads to harsh conditions for the survival of the rivers flora and fauna. A demonstrative indicator of environmental troubles is the intensive development of blue-green algae, which are a nutrient medium for cyanobacteria. Their productivity can be limited by hydromechanical capture. It is proposed to use a small-sized mobile vessel with a filter unit using replaceable cartridges and a pump. As a filter material, it is recommended to use crushed reeds. This technical solution allows the environmentally safe disposal of biomass, saturated with phytoplankton and heavy metal ions that are effectively absorbed. An equation of the distribution of concentrations of blue-green algae over the distance measured from the water surface is provided. The calculated data obtained from the proposed dependence allow us to determine the required level of immersion of the suction probes. The optimal time period in days for the operation of filtering units during summer season was revealed.
\end{abstract}

\section{Introduction}

The urgent problem for metropolises and large cities, especially with powerful industrial centers, is the low quality of water resources. As a rule, subject to processing and transportation technologies, water supply from underground sources is satisfactory. A completely different situation occurs when using the resources of water bodies running through the territories of regions with a high population density.

The historical formation of settlements, and subsequently large cities on the main waterways, was predetermined by two main reasons: water demand for household needs (it was in abundance with such arrangement of buildings and cultivated areas) and opened up great opportunities for convenient transportation. Then, due to the active development of production activities, consumption increased significantly, which could be ensured by existing nearby rivers and lakes. At high rates of industrialization and the emergence of new high-tech industries, the construction of water bodies with huge reserves of fresh water was required. However, the effective solution of deficit issues through the creation of

"Corresponding author : irkyt-44@yandex.ru 
reservoirs, the prevailing ecosystems in the occupied territories were irretrievably violated, and the negative pressure on the environment increased.

The current trend of intensive consumption of water resources, along with the imbalance introduced, causes pollution of surface sources by wastewater discharge after treatment facilities. Given the low efficiency of technological treatment cycles, wastewater entering in large volumes into rivers or reservoirs significantly worsens the quality of the habitat required to preserve the species diversity of river flora and fauna. Given that the decay time of harmful substances discharged into water bodies has a rather long period, their inevitable accumulation occurs, which poses a serious threat to the subsequent emergence of an environmental disaster. Therefore, wastewater quality indicators must be achieved at biological treatment plants so that the impurities contained in them would not cause damage to water bodies and thereby ensure the safe use of surface sources for industrial, domestic and fishery needs.

Despite rather strict legislative requirements for wastewater treatment, as well as the reduction in consumption by industrial enterprises and the population, the ecological state of water bodies in regions with large industrial centers is often of concern. Their intense pollution occurs for a number of main reasons: violations in the operating modes of treatment facilities, a mismatch with the high technical level of treatment technology and deterioration of equipment. In addition, there are other sources of pollution, which include surface runoff from residential and agricultural areas, as well as soil erosion in coastal areas. All that creates an environmental threat both for the water body itself (degradation of aquatic flora and fauna) and for the population as a whole, having a negative impact on the health of the nation.

\section{Materials and methods}

As a result of the pollution, biogenic elements such as nitrogen, potassium, calcium, sodium, sulfur, phosphorus, carbon, and chlorine enter water bodies. Their presence during natural water metabolism ensures the normal functioning of organisms, but significant concentrations, especially in soluble organic substances coming from sewage, are the reason for the intensive development of algae, contributing to the eutrophication of water bodies. The latter can be caused not only by anthropogenic influences, but also by the natural aging of the habitat in a water body. In prosperous ecosystems, the development of algae contributes to the formation of a richer food base for fish and other aquatic organisms, but at high growth rates caused by anthropogenic influences an additional deterioration in water quality occurs due to the so-called "flowering", turbidity and a decrease in oxygen content. At low visibility indices, the photosynthesis of algae growing on the bottom ceases and their dying off occurs, exacerbating the ecological situation. The high degree of eutrophication of water bodies achieved in this case causes the river fauna to freeze. Therefore, the intensity of growth of concentrations of blue-green algae during the "flowering" period of water is a fairly clear indicator of the ecological state of the water body. The main reasons for increasing the reproduction of cyanobacteria include the decrease in the flow rate, the formation of stagnant, well-heated shallow water and the intake of a significant amount of nutrients in the composition of dissolved organic substances. Since blue-green algae are extremely viable species of phytoplankton, they immediately respond to any environmental threat, adapting to new conditions [1-4]. They change the pace of their development depending on the hydrodynamic parameters of water bodies, weather conditions and the availability of essential nutrients. Since the vegetative period of blue-green algae is short, intensive reproduction leads to the death of a large amount of phytoplankton, which contributes to the accumulation of detritus that settles in the deep zone. The resulting biomass is a nutrient medium for destructors, which consume 
oxygen during their lifetime, reducing its concentration in water. In the absence of oxygen, bacteria-destructors survive due to anaerobic digestion to more auspicious conditions. As a result, the content of dissolved oxygen varies in depth, significantly decreasing in the bottom zones.

After the death of phytoplankton, the biogenic elements digested by it during the subsequent decomposition of detritus are again released at the bottom and then transported by ascending convective flows to the surface, where they are again consumed by viable cyanobacteria. Thus, the cycle of biogenic pollution is not only repeated, but also exacerbated. During intensive "blooming", water may contain up to 200 various chemical elements and compounds that pose an environmental threat [5-7]. A high concentration of blue-green algae contributes to the accumulation of acetone, butyl alcohol, acetic and butyric acids, phenols, mercaptans, amines, and indole-containing components. These processes are accompanied by a decrease in the $\mathrm{pH}$ of water to 5-4 and lower, as well as an increase in the temperature of the saturation zone of phytoplankton relative to the average statistical by $6-8{ }^{\circ} \mathrm{C}$ [5-7]. The latter, in turn, contributes to the intense evaporation of algal metabolites, causing air pollution and specific unpleasant odor. It should also be noted that a significant amount of dissolved organic compounds serves as a breeding ground for the preservation and development of pathogenic microflora, which exacerbates the adverse sanitary and epidemiological situation [8.9].

If difficulties in achieving the required quality of wastewater arise, it is necessary to timely eliminate the consequences of biogenic pollution in order to prevent critical conditions in the ecological balance of water bodies. The development of eutrophication can be overcome by a fairly reliable and effective way of dealing with excess phytoplankton, based on the hydromechanical principle of filtering water resources [10, 11]. The devices of simple construction used in this case provide a directed effect on the epicenter of cyanobacterial reproduction, which helps to localize areas of increased biogenic pollution, preventing them from spreading. It is advisable to utilize collected biomass on disposable filter nozzles filled with shredded coarse aquatic vegetation, since the proteins and carbohydrates contained in phytoplankton are high quality raw materials for the production of biogas after higher calorie fats. Given the percentage ratio in terms of alternative fuel reproduction [12], under favorable anaerobic digestion conditions, up to $1300 \mathrm{~m}^{3}$ of biogas can be obtained from 1 ton of fat, and up to $780 \mathrm{~m}^{3}$ from proteins and carbohydrates of the same mass. This is confirmed by the results of experimental studies [13] of fermentation of raw phytoplankton in volumes of $1 \mathrm{dm}^{3}$ for a week at a temperature of 20-30 ${ }^{\circ} \mathrm{C}$. The anaerobic process was accompanied by the formation of $700 \mathrm{ml}$ or more of gas with a composition of $65 \%$ methane $\left(\mathrm{CH}_{4}\right)$, up to $30 \%$ carbon dioxide $\left(\mathrm{CO}_{2}\right)$ and an average of $1 \%$ of the following components $\mathrm{H}_{2}, \mathrm{H}_{2} \mathrm{~S}, \mathrm{O}_{2}$ and $\mathrm{N}_{2}$ [13]. According to other data, in the conversion of $1 \mathrm{~kg}$ of dry mass of algae [14] at a temperature of $32^{\circ} \mathrm{C}$, biogas is produced with a volume of $0.8-1 \mathrm{~m}^{3}$, the composition of which has practically the same indicators for the content of various impurities in methane. The amount of gas released depending on the type of utilized algae is given in the studies [15]. However, filter fillers saturated with phytoplankton during the cleaning of biogenic pollution zones do not allow evaluating the ratios of various ichthyoflora species detained in them. Therefore, in this situation, to assess the possible reproduction of biogas, one should use the averaged values obtained taking into account the actual moisture content of the raw materials sent to anaerobic digestion.

To address the issues of effective cleaning of water bodies from the effects of biogenic pollution, one should consider the distribution of phytoplankton forming in the warm season of the year in depth in zones of environmental disaster. As already noted, near the surface of the water, active photosynthesis occurs and, accordingly, favorable conditions 
contribute to the high reproduction of cyanobacteria, which primarily leads to their distribution in the upper layers. Therefore, the suction devices of the filtering installations should be located closer to the surface of the water and with a limitation of the depth of their immersion. It is possible to determine the appropriate range in height of the location of the probes for collecting biomass when analyzing the process of structural formation of cyanobacterial colonies in the aquatic environment. With active photosynthesis in the upper zone caused by the unhindered penetration of solar radiation, the differential equation for the distribution of the concentration of blue-green algae taking into account the hydrodynamics of the channel will look as follows:

$$
\frac{d C}{d z}=\frac{m_{s}}{v}-\frac{C}{h},
$$

where $C$ is the concentration of blue-green algae, $\mathrm{g} / \mathrm{m}^{3} ; z$ is the vertical axis directed from the surface of the water to the bottom of the reservoir, $\mathrm{m} ; v$ - water flow rate, $\mathrm{m} / \mathrm{s}$; $\mathrm{h}$ is the height of the zone of intense photosynthesis, depending on the turbidity of the water, and the average taken equal to $1 \mathrm{~m} ; m_{s}$ is the specific mass rate of formation of blue-green algae in $1 \mathrm{~m}^{3}$ of the aquatic environment, $\mathrm{g} /\left(\mathrm{s} \cdot \mathrm{m}^{3}\right)$. The change in the concentration of blue-green algae along the depth measured from the surface of the water primarily depends on the dynamic assimilation of the formed cyanobacteria and their accumulation in the intensive growth zone at the age corresponding to the end of the vegetative period, which is taken into account in expression (1). The solution to equation (1), including the listed components, is the dependence :

$$
C=\frac{m_{s} h}{v}+c e^{-\frac{z}{h}} .
$$

To determine the constant integration $c$ as the boundary condition, we use the assumption that the concentration of blue-green algae on the surface of the water, that is, at $z=0$, will be equal to the maximum value determined by the level of biogenic pollution of the reservoir. Then expression (2) becomes :

$$
C=\frac{m_{s} h}{v}+\left(C_{m}^{B}-\frac{m_{s} h}{v}\right) e^{-\frac{z}{h}} .
$$

The obtained equation (3) allows us to analyze the structure of the formation of colonies of cyanobacteria by the height of shallow waters at various degrees of pollution of water bodies.

\section{Results}

As shown by previous studies, the daily mass formation rate of blue-green algae, depending on the amount of dissolved organic substances, is in the range from 0.1 to $0.5 \mathrm{~g} /\left(\right.$ day $\left.\cdot \mathrm{m}^{3}\right)$, therefore, the specific mass velocity $m_{s}$, which is included in the expression (3) may have values in the range from $1.16 \cdot 10^{-6}$ to $5.79 \cdot 10^{-6} \mathrm{~g} /\left(\mathrm{s} \cdot \mathrm{m}^{3}\right)$. The flow velocity in the expansion zones of blue-green algae, as a rule, does not exceed $0.5 \mathrm{~m} / \mathrm{s}$. Therefore, given the values of these parameters, the ratio $m_{s} h / v$ has a weak effect on the distribution of concentrations over the depth of the aquatic environment. Fundamental in this process is the photosynthesis of phytoplankton, which floats to the surface to absorb solar radiation and nutrients. 
Consider the distribution of blue-green algae along the depth of a reservoir with varying degrees of biogenic pollution. The concentration changes shown in Fig. 1 and obtained by dependence (3) for a rather problematic environmental situation with reaching the maximum value of $0.15 \mathrm{~g} / \mathrm{m}^{3}$, as well as for more dangerous biogenic pollution, corresponding to $0.2 \mathrm{~g} / \mathrm{m}^{3}$ and to $0.25 \mathrm{~g} / \mathrm{m}^{3}$, show that it is the first meter zone that is subject to active saturation with phytoplankton. Therefore, to clean the reservoir, the suction devices should be located not lower than $1 \mathrm{~m}$, and if possible, the depth of immersion should be rigidly fixed, they should be in the range from 0.05 to $0.5 \mathrm{~m}$ according to the distribution of concentrations.

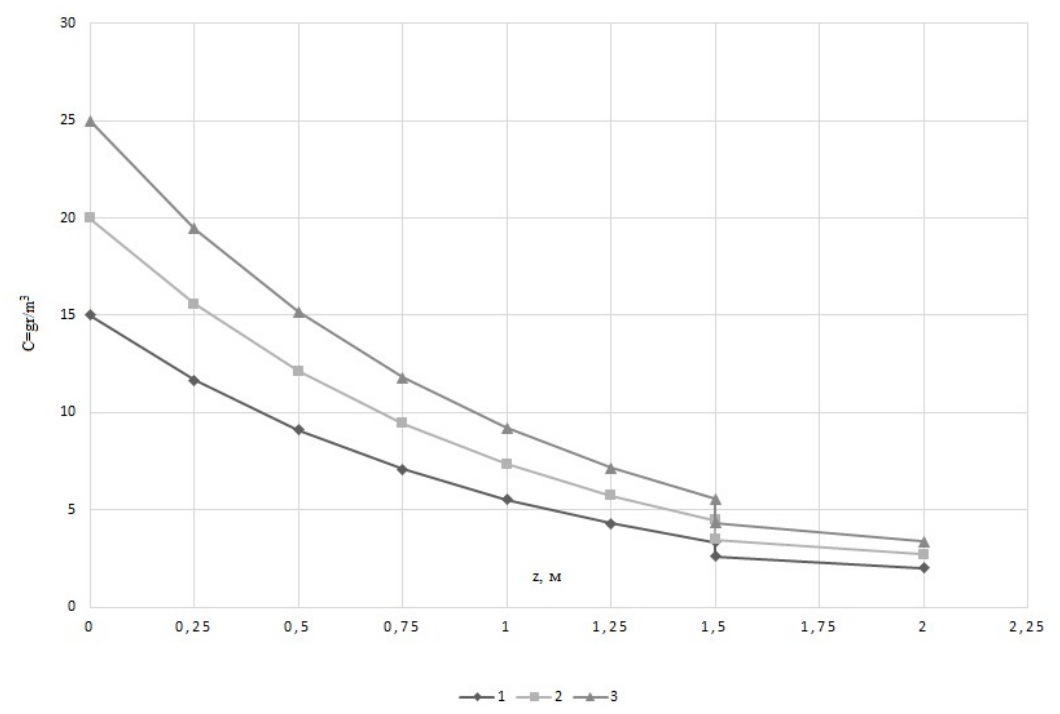

Fig. 1. Change in the concentration of blue-green algae in depth from the surface of the water: 1 with a maximum content of blue-green algae $C_{m}^{B}=0.15 \mathrm{~g} / \mathrm{m}^{3} ; 2$ - at $C_{m}^{B}=0.2 \mathrm{~g} / \mathrm{m}^{3}$;

3 - at $C_{m}^{B}=0.25 \mathrm{~g} / \mathrm{m}^{3}$

Given the distribution of concentrations (Fig. 1), it should be noted that after the first hydromechanical treatment of the ecological disaster zone, it is advisable to re-remove the surfaced blue-green algae after a day, thereby preventing the rapid restoration of cyanobacteria colonies. Subsequently, with a possible change in weather conditions, eutrophication can slow down significantly, which will favorably affect the habitat for ichthyofauna. For the effective organization of hydromechanical cleaning of water bodies, the operation of the devices should be limited to the period of activation of phytoplankton, namely from 10:00 to 16:00 hours. By setting immersion probes to the optimum depth and pumping water through a filter nozzle filled with shredded hard vegetation, not only the problem of removing phytoplankton is solved, but it also stimulates updating of the river flora, the aging and dying of which also contributes to eutrophication. Large hydrophytes, such as reeds or cattail during the vegetative period, are able to extract biogenic elements from water in large quantities, contributing to the natural cleaning of water bodies. For example, a dense mature reed thicket with an area of 1 ha can accumulate up to 6 tons of various mineral substances, including $\mathrm{K}-859 \mathrm{~kg}, \mathrm{~N}-167 \mathrm{~kg}, \mathrm{P}-122 \mathrm{~kg}, \mathrm{Na}-451 \mathrm{~kg}, \mathrm{~S}-$ $277 \mathrm{~kg}$ and $\mathrm{Si}-3672 \mathrm{~kg}[1,16]$. Assimilating the listed elements, the reed performs cleaning functions in the reservoir, but only if its thickets will be updated every year by mowing. Cutting and removing this type of coarse algae, crushing and filling filter 
cartridges with it, and then through floating stations trapping phytoplankton and other impurities on them, the habitat for the river flora can be significantly improved. In addition, the sorbing properties of the reed allows the purification of water from heavy metal ions by their absorption by the porous structure of the nozzle.

The collected concentrated biomass can be sent for anaerobic digestion into the digesters of urban wastewater treatment plants or, in the absence thereof, with a minimum content of harmful substances, be added into the soil as fertilizer, since it is rich in nutrients. However, further disposal of the collected phytoplankton is preferable in a biogas plant. The reed, recommended for use for disposable nozzles, also has high methanogenesis during anaerobic digestion, which makes it possible to efficiently utilize the total biomass [17-20].

\section{Conclusion}

Biogenic pollution of water bodies, especially of artificial origins, at high temperature conditions in the summer seasons leads to a significant increase in the reproductive ability of cyanobacteria. In order to avoid intensive "blooming" of water in shallow water heated by solar radiation, it is advisable to periodically capture blue-green algae through floating filtering stations. The suction devices of the stations, in accordance to the obtained equation for the distribution of phytoplankton concentrations, should be located at a depth of 0.05 to $0.5 \mathrm{~m}$ from the surface of the water. Shredded reeds should be used as the filler for disposable filter cartridges. Such plants not only make it possible to collect excess phytoplankton, but also sorb heavy metal ions by absorbing them by the porous structure of hard aquatic vegetation filling the nozzles. Disposal of the collected biomass and cartridge filler should be carried out by anaerobic digestion, i.e. sent to the digesters of urban wastewater treatment plants or biogas plant reactors.

The proposed method for improving the environmental safety of water bodies by means of floating filtering stations allows phytoplankton capture not only to remove biogenic elements absorbed by blue-green algae, but also to additionally clean shallow water from hard ichthyoflora used to fill cartridges. All this together will cause positive dynamics in the state of water bodies under the existing threat of intense eutrophication.

\section{References}

1. L.A. Kulsky, L.A. Sirenko, Z.N. Shkavro, Phytoplankton and water (Kiev: Science. Dumka, 1986) 135

2. V. B. Mikhno, A. I. Dobrov, Landscape and environmental features of reservoirs and ponds of Voronezh region (Voronezh: Voronezh St. Pedagogical Un., 2000) 185

3. G.S. Seydaliev, I.I. Kosinova, T.V. Sokolova, K.Y.Silkin, Ecological management of the territories of the Voronezh reservoir (Voronezh: Origins, 2017) 186

4. A.Y. Scriabin, G.V. Popovyan, I.A. Tron, Water supp. \& sanitary equip., 4 5-8 (2017)

5. E.S. Gogina, Removal of biogenic elements from wastewater (M.: MGSU, 2010) 120

6. R. Song, S. Yang, H. Xu, Z. Wang, Y. Chen, Y. Wang, Int. J. Environ. Res. Public Health, 15(1) 101 (2018)

7. L. Shang, M. Feng, X. Xu, F. Liu, F. Ke, W. Li, Toxins, 1026 (2018)

8. V. Shcherbakov, E. Gogina, T. Schukina, N. Kuznetsova, N. Makisha, Int. J. of Appl. Eng. Res. 10(24) 44353-44356 (2015)

9. V.I. Shcherbakov, B.M. Kumedov, Forest J. 4 133-137 (2015)

10. V.M. Shmandiy, V.V. Nikiforov, V.P. Alferov, E.V. Kharlamova, V.A. Pronin, Hygiene and Sanitation 6 35-37 (2010) 
11. W. Czyżewska, M. Piontek, Toxins 11285 (2019)

12. V. Shcherbakov, V. Pomogaeva, K. Chizhik, E. Koroleva, Advances in Intelligent Systems and Computing, 983 361-372 (2019)

13. V.P. Alferov, V.A. Promin, V.M. Shmandy, V.V. Nikiforov, S.V. Degtyar, E.V. Kharlamova, Env. safety 3 1(9) 9-13 (2010)

14. F. T. Shumakov, Scientific notes of Taurida Nat. Un., Ser. Geography 23(62) \#2 286$295(2010)$

15. L. Moeller, A. Bauer, H. Wedwitschka, W. Stinner, A. Zehnsdorf, Energies 11(11) $3016(2018)$

16. R. Song, S. Yang, H. Xu, Z. Wang, Y. Chen, Y. Wang, Int. J. Environ. Res. Public Health 15101 (2018)

17. V. Nykyforov, M. Malovanyy, T. Kozlovs'ka, O. Novokhatko, S. Digtiar, E-Eur. J. of Enterprise Technol. 5/10(83) 11-18 (2016)

18. C. Rodriguez, A. Alaswad, J. Mooney, T. Prescott, et al, Fuel Process. Technol. 138 765-779 (2015)

19. M. P. Caporgno, R. Trobajo, N. Caiola, C. Ibanez, et at, Renew. Energy. 75 374-380 (2015)

20. V.A. Milyutkin, S.A. Tolpekin, I.V. Borodulin, E.A., Collection of articles on the materials of the II All-Russian (national) scientific-practical conference 104-109 (2018) 